\title{
Desenvolvimento e avaliação de sistema multimídia para ensino e aprendizado em topografia
}

\author{
Cláudio Silva Soares \\ Tales Anderson Dias Mouzine \\ Robson Pequeno
}

SOUSA, RP., MIOTA, FMCSC., and CARVALHO, ABG., orgs. Tecnologias digitais na educação [online]. Campina Grande: EDUEPB, 2011. 276 p. ISBN 978-85-7879-065-3. Available from SciELO Books $<$ http://books.scielo.org $>$.

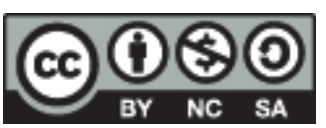

All the contents of this work, except where otherwise noted, is licensed under a Creative Commons Attribution-Non Commercial-ShareAlike 3.0 Unported.

Todo o conteúdo deste trabalho, exceto quando houver ressalva, é publicado sob a licença Creative Commons Atribuição Uso Não Comercial - Partilha nos Mesmos Termos 3.0 Não adaptada.

Todo el contenido de esta obra, excepto donde se indique lo contrario, está bajo licencia de la licencia Creative Commons Reconocimento-NoComercial-CompartirIgual 3.0 Unported. 


\title{
Desenvolvimento e avaliação de sistema multimídia para ensino e aprendizado em topografia
}

\author{
Cláudio Silva Soares \\ UEPB - Campina Grande, Paraíba \\ claudio.uepb@yahoo.com.br \\ Tales Anderson Dias Mouzine \\ UEPB - Campina Grande, Paraíba \\ Robson Pequeno \\ UEPB - Campina Grande, Paraíba \\ robson.pequeno@gmail.com
}

\section{Introdução}

A Topografia é uma ciência aplicada, com fundamentos na Geografia e na Trigonometria, que tem por fim representar graficamente, num plano topográfico, os detalhes requeridos de uma parte limitada da superfície da terra, de forma que eles guardem no desenho posições altimétricas e planimétricas relativas às existentes no terreno. A projeção horizontal se chama "planta".

O surgimento das mídias eletrônicas, que divulgam o conhecimento produzido e o acesso à informação que, por sua vez, se 
constituem pilares da educação ocidental moderna, acontecem de forma cada vez mais ágil e, com isto, os critérios de perenidade e permanência dos conhecimentos acumulados se somam ao critério de atualidade (CARVALHO, BOTELHO, 2000).

De acordo com Moreira (1986), o processo de informatização da educação deve ser considerado como meio de ampliação das funções do professor, favorecendo mudanças nas condições e no processo ensino-aprendizagem. A modernização das técnicas de ensino, no entanto, só logrará êxito se usada de forma crítica pelos usuários, de modo geral, visto que deverá estar associada a cada realidade educativa e fundamentada em princípios psicopedagógicos que explicitem certa concepção de ensino e aprendizagem. Em termos pedagógicos, pode-se afirmar que a didática de mídia ainda segue muitos conceitos da tecnologia instrucional tradicional, visto se basear em psicologia comportamentalista (behaviorista), cujos passos básicos são: a análise da tarefa; o avanço em pequenos e progressivos passos de aprendizagem; a participação ativa do estudante; a velocidade de aprendizagem individual e a realimentação imediata do esforço.

O software educacional pode ser visto tanto como uma construção técnica como recurso pedagógico. Do ponto de vista técnico, compreende a parte computacional e é avaliado em termos de sua organização lógica e desempenho. Quanto ao fato de ser um recurso pedagógico, a principal questão corresponde à contribuição do software para o ensino e aprendizagem do seu público alvo (FOCKING, 2001).

Segundo Brandão (1998), o conhecimento das características que tornam o software adequado ou não ao processo ensinoaprendizagem, das modalidades de interação que estabelece com o usuário e de sua inter-relação com os objetivos educacionais em específicas situações de ensino, é de fundamental importância para o êxito da relação entre informática e educação. 
Para Oliveira (1998, apud FOCKING 2001), o software educacional é um programa de computador que possui uma proposta de ensino, com um objetivo educacional predefinido, que se propõe a auxiliar na aprendizagem de conteúdos e habilidades, mediante a utilização de uma interface computadorizada. O software deve possuir recursos que auxiliem no processo de aquisição de determinado conhecimento, promovendo situações estimulantes para o aluno, não apenas despertando a sua atenção, mas mantendo-a ao longo de sua interação. Para que este propósito seja atingido, os conteúdos pedagógicos apresentados no software educacional devem ser claros, consistentes, compreensíveis. Recursos multimídia e recursos motivacionais devem provocar o interesse pelo assunto ao mesmo tempo em que facilitam a relação ensino/ aprendizagem.

Há, portanto, o consenso de que o software educacional deve atender aos objetivos específicos e fazer uso de recursos que potencializem o processo não só de aquisição, mas também, de reforço de determinados conhecimentos e habilidades, estimulando o desenvolvimento cognitivo do usuário, permitindo um aprendizado expressivo.

Neste sentido, o objetivo deste trabalho foi desenvolver e avaliar um software educacional sobre topografia, com recursos multimídia, destinado ao meio acadêmico das ciências agrárias.

\section{Material e métodos}

O presente trabalho foi constituído a partir de uma equipe multidisciplinar, por profissionais das áreas de engenharia agrícola e ciência da computação. A estrutura do curso básico de topografia foi programada de tal maneira que o usuário possa acessar livremente as diferentes unidades do CD-ROM, usando 
a estrutura hipermídia, de forma seqüenciada. O desenvolvimento do software foi constituído das seguintes etapas: a) Planejamento - Onde foi delineado o objetivo principal do projeto, definidos e organizados os conteúdos, assim como seus tópicos e sub-tópicos. O tópico escolhido, dentro da disciplina Topografia, foi a Planimetria. Também foram escolhidos os tipos de mídias que deveriam constar no curso de acordo com o tópico abordado, e também foi definido o público alvo ao qual interessaria o sistema multimídia. b) Interação - Fase em que foi discutida a estrutura do CD-ROM, em termos de conteúdo e de distribuição dos tópicos e sub-tópicos. c) Instanciação - Corresponde à parte operacional do software e aos conceitos de hipermídia, onde foram criados os mapas de informação para apresentação do conteúdo. Esta etapa foi usada para se definir as navegações e estruturas de acesso nas entidades e blocos de informações. d) Story Board e Script Book - A confecção dos Story Boards e Script Books consistiu na elaboração das informações visuais e dos comandos mostrados em cada tela. e) Projeto da Interface - Esta etapa foi de responsabilidade do programador visual que, de posse das informações coletadas na fase de interação e com os Story Boards e Scripts Books em mãos, passou a dar forma a cada tela do CD-ROM. f) Escolha das Mídias -Esta etapa foi desenvolvida logo após a elaboração dos Story Boards e Script Books, paralelamente à etapa de interface. g) Autoria - Consistiu em implementar o projeto numa linguagem computacional com recursos hipermídia. A ferramenta utilizada neste projeto foi o Flash MX. Sua escolha deveu-se à facilidade de uso e aos vários recursos de mídias. h) Validação - Após a implementação pela autoria obteve-se um protótipo do CD-ROM para fazer uma avaliação técnica. A etapa de validação do CD-ROM foi a última fase em que foram permitidas alterações de conteúdo, podendo acarretar mudanças nas fases anteriores. i) Teste Terminada a aplicação, foram feitas as avaliações necessárias para validação do produto. Após os testes, o software ficou pronto para reprodução e comercialização. 
$\mathrm{Na}$ determinação deste universo amostral para avaliar a usabilidade do software proposto foram escolhidos participantes com perfis afins, ou seja, alunos que já tinham sidos aprovados na disciplina de Topografia em semestres anteriores e professores que possuíam conhecimentos nesta área, o que possibilitou a discriminação das três categorias de usuários de teste necessárias - estudantes de nível médio do curso Técnico em Agropecuária, estudantes de graduação do curso de Licenciatura em Ciências Agrárias e, professores destes cursos, ambos da Universidade Estadual da Paraíba, Campus IV, em Catolé do Rocha-PB.

Para avaliação do sistema multimídia foram distribuídas cópias do CD-ROM a estes participantes, quando foi solicitado que cada participante da pesquisa, 47 pessoas envolvidas, avaliasse o CD-ROM como um todo, sob diferentes aspectos, para que se pudesse responder às fichas de avaliação. Essas fichas constaram de questionários aplicados com a finalidade de avaliar a função educacional do sistema multimídia na disciplina de topografia.

Os resultados obtidos foram separados por grupo avaliado: Grupo A (estudantes de nível técnico), Grupo B (estudantes de nível superior) e Grupo C (professores da área de Ciências Agrárias), sendo os dados agrupados por categoria avaliada: interface, conteúdo e interatividade.

Do modelo das fichas de avaliação adotadas na pesquisa, foi aplicada uma escala de Likert de cinco pontos, sendo a resposta de cada questão representada da seguinte maneira: péssimo $=1$; ruim $=2$; regular $=3$; bom $=4$ e excelente $=5$. Para análise geral dos dois grupos de alunos (técnico e superior), foram utilizadas as notas atribuídas a cada resposta da escala de Likert, citada no parágrafo anterior, em que as mesmas variaram de 1 a 5 . A partir dessas notas foi determinada a média dos pontos, conforme 
metodologia descrita por Berenson e Levine (1992), da qual foi adaptada para a seguinte fórmula:

$$
\mathbf{M P}=\frac{(P 1 \cdot N a)+(P 1 \cdot N a)+(P 1 \cdot N a)+(P 1 \cdot N a)+(P 1 \cdot N a)}{N T a}
$$

Onde: $\mathrm{MP}=$ Média dos pontos; $P 1, P 2, P 3, P 4$ e P5= Pontos referentes às notas atribuídas às respostas da escala de Likert, , ou seja, 1, 2, 3, 4 e 5, respectivamente; $N a=$ Número de alunos que atribuíram cada ponto individualmente da escala de Likert e, $N T a=$ Número total de alunos envolvidos na pesquisa.

\section{Resultados e discussão}

\section{Apresentação das principais telas do software}

O software elaborado neste trabalho foi denominado "Guia Prático para Levantamento Planimétrico", sendo executável e desenvolvido em ambiente Windows, porém pode ser executável em outros ambientes que possuam o Macromedia Flash Player. O curso do CD-ROM possui uma interface simples e apresenta o conteúdo em páginas seqüenciais. A tela principal é ilustrada na Figura 1. 


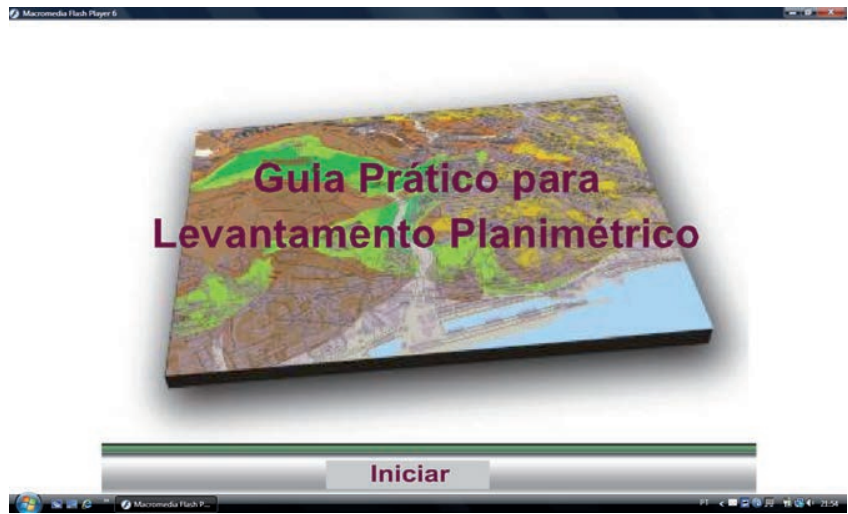

Figura 1 - Acesso inicial às telas do CD-ROM.

Após iniciar o software, nas próximas páginas há uma introdução sobre a Topografia e suas divisões. Nessa fase o software aborda alguns conceitos relacionados às grandezas medidas num levantamento topográfico como ângulos horizontais e verticais. Além das explicações na forma de texto, essas grandezas foram ilustradas com animações como mostram as figuras 2 e 3 a seguir.

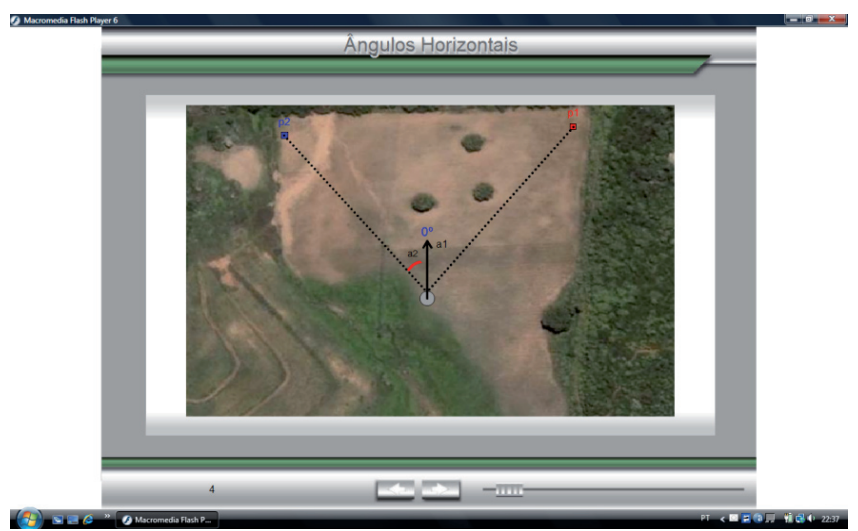

Figura 2 - Animação e demonstração em flash dos ângulos verticais. 


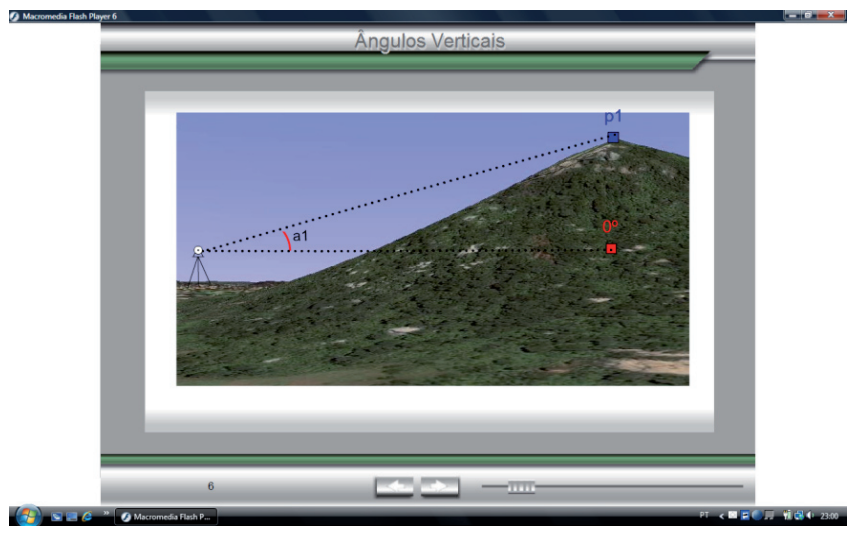

Figura 3 - Animação e demonstração em flash dos ângulos horizontais.

Nas próximas telas, através de textos, foram explanados os conceitos referentes à medida direta de distância, onde estão inseridas as grandezas lineares como distâncias horizontais, verticais e inclinadas. Em seguida, esses conceitos foram reforçados com animações gráficas mostrando cada uma dessas grandezas (Figura 4).

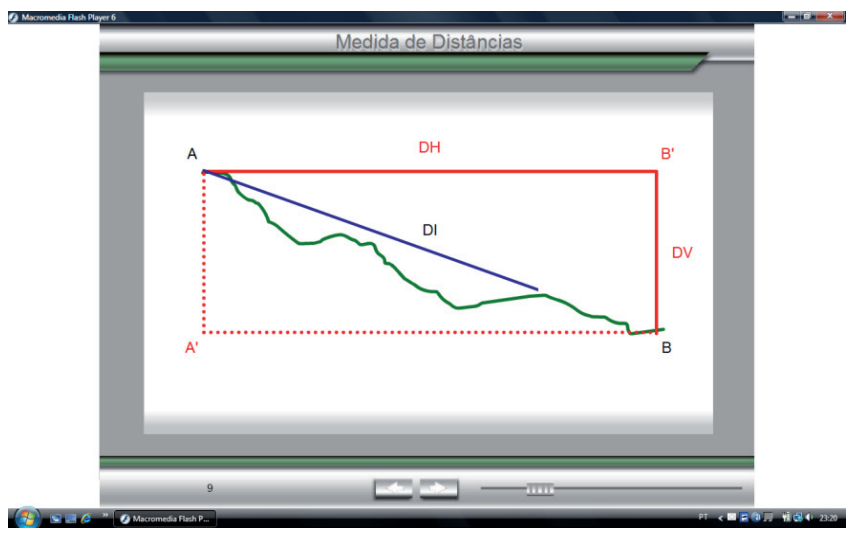

Figura 4 - Animação e demonstração das distâncias horizontais, verticais e inclinadas. 
Ainda no tópico medida direta de distância, foram demonstrados os dispositivos utilizados para determinação dessas grandezas (Figura 5). Também foram demonstrados os dois métodos de determinação direta dessas distâncias (Figura 6 e 7), enfatizando sempre as maneiras corretas de aplicação no campo. Essas animações são bastante importantes do ponto de vista prático, pois representa de maneira muito clara o modo como se procede em um levantamento topográfico.

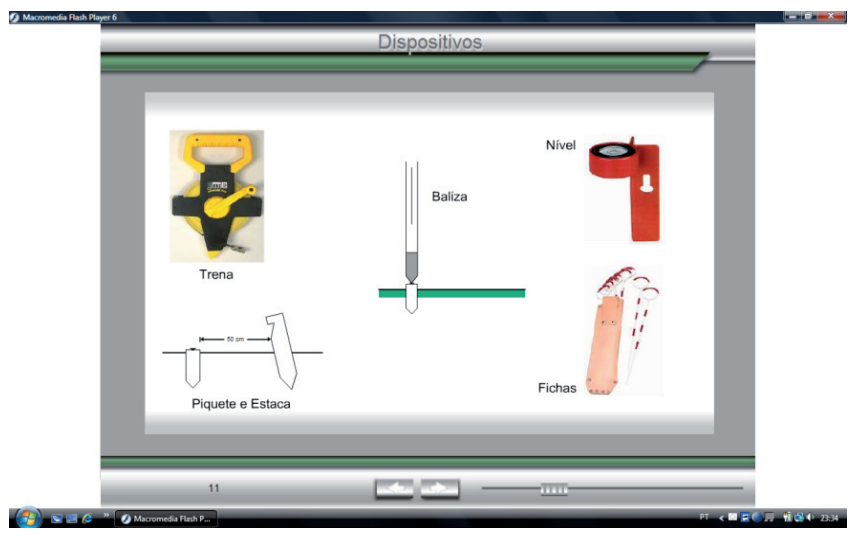

Figura 5 - Dispositivos utilizados na determinação das distâncias.

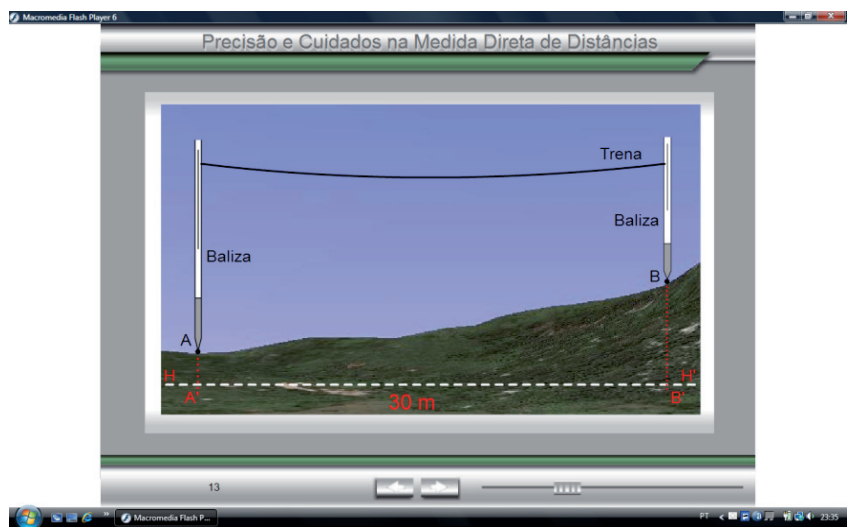

Figura 6 - Determinação direta de distâncias horizontais com lance único. 


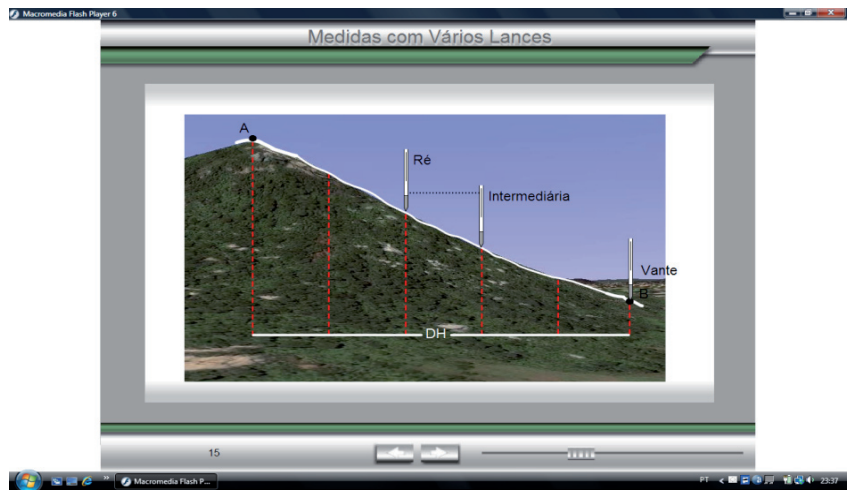

Figura 7 - Determinação direta de distâncias horizontais com vários lances.

No tópico seguinte, foram mostrados os conceitos e as animações referentes às medidas indiretas de distância. Neste segmento foram ilustrados os equipamentos (Figura 8), algumas formas de leitura dos mesmos (Figura 9) e, os métodos dessas medidas indiretas (Figura 10).

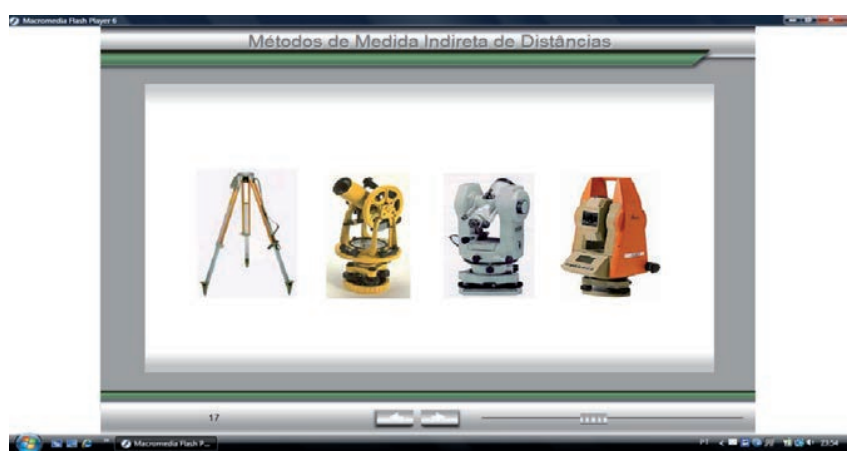

Figura 8 - Equipamentos utilizados na determinação indireta de distância. 


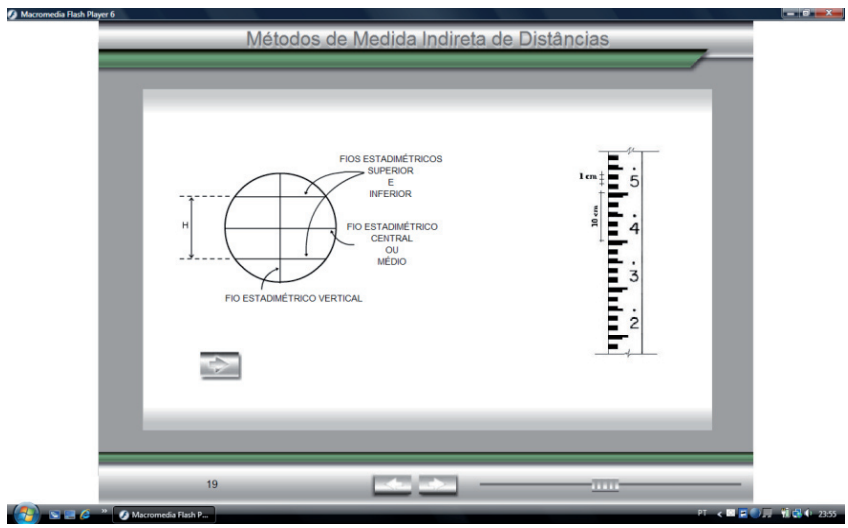

Figura 9 - Animação da leitura da régua para determinação indireta de distância.

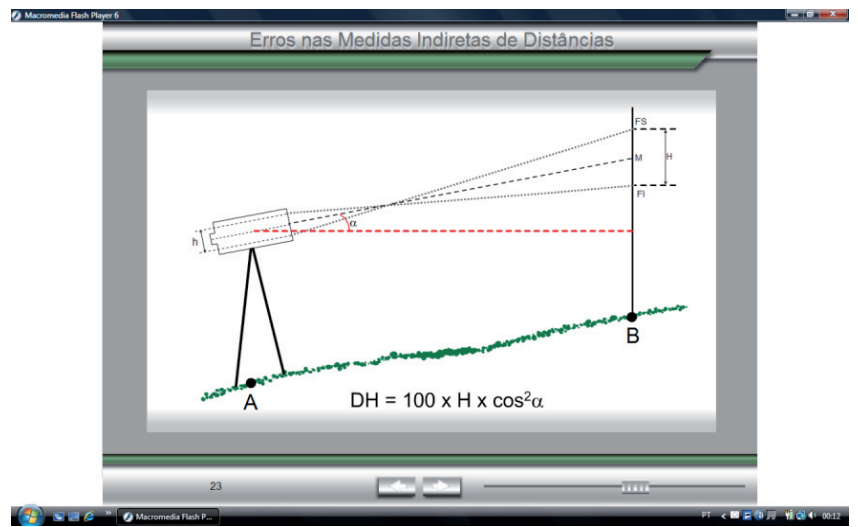

Figura 10 - Leitura dos equipamentos utilizados na determinação indireta de distância. 
Os métodos de levantamento planimétricos foram explicados através de textos, e demonstrados por meio de animações que facilitaram o aprendizado dos alunos na disciplina de topografia (Figuras 11 e 12).

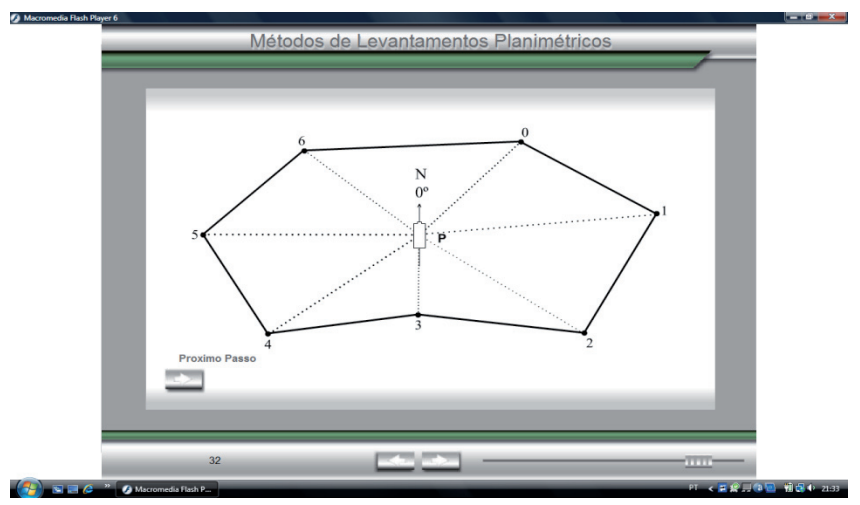

Figura 11 - Demonstração do método de levantamento planimétrico por interseção utilizado na determinação indireta de distância.

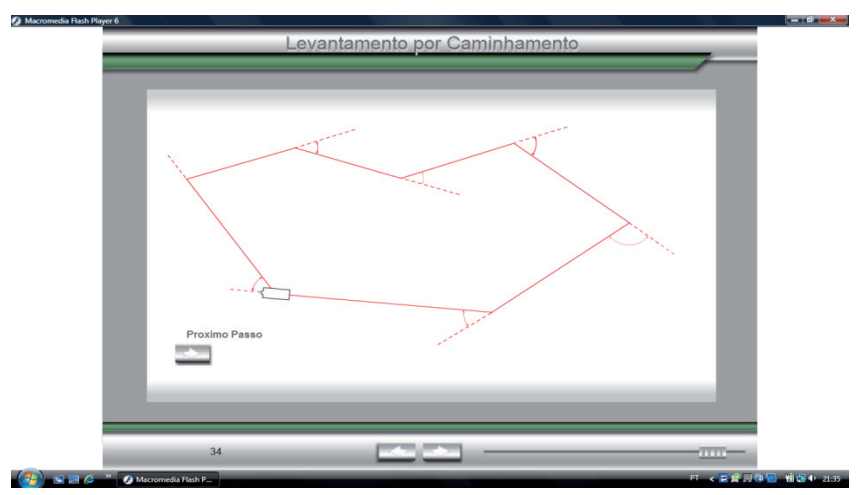

Figura 12 - Método de levantamento planimétrico por caminhamento. 


\section{Resultados provenientes dos apêndices}

Os resultados referentes às respostas do questionário, aplicado aos alunos e professores, estão dispostos nas figuras 13 a 22, sendo discutidos logo abaixo.

A facilidade de acesso e uso das telas do CD-ROM foi avaliada pelos alunos e professores e apresenta seus resultados na Figura 13. Verifica-se, portanto, que as respostas foram semelhantes entre alunos do curso técnico e superior, pois a maioria classificou essa característica entre boa e excelente. Quando avaliado por professores, a facilidade e uso das telas se mostraram de forma excelente para todos esses avaliadores (100\%). Quando calculada a média dos pontos dos dois grupos de alunos (tecnolandos e graduandos), obteve-se uma nota 4,5 na escala de Likert para essa característica avaliada. Dessa forma, o CD-ROM cumpriu o objetivo de permitir ao usuário um manuseio de suas telas de forma simples, rápida e eficiente.

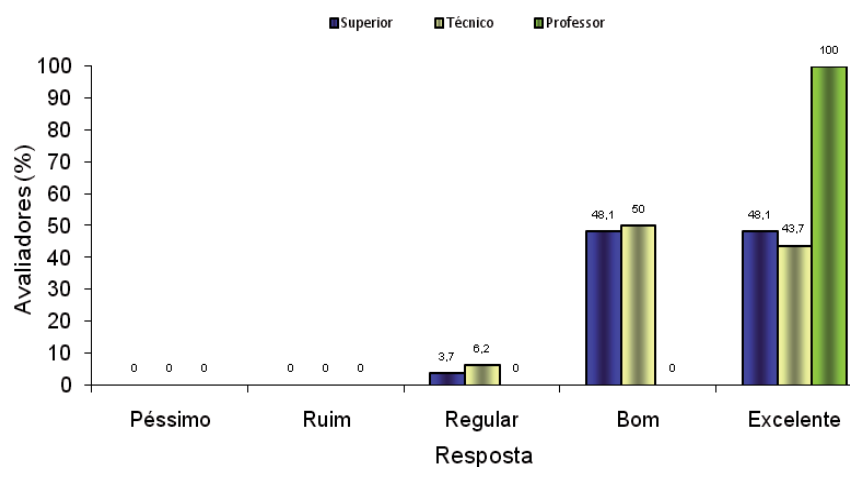

Figura 13 - Avaliação da facilidade de acesso e uso das telas do CD-ROM.

Resultados semelhantes também foram obtidos por ZemMascarenhas e Cassiani (2001) quando avaliaram um software educacional para ensino de enfermagem pediátrica, pois os mesmos 
verificaram que a qualidade da interface de seu programa foi considerada excelente pela maioria dos avaliadores $(80,27 \%)$.

Com relação à sequência dos tópicos distribuídos no CD-ROM (Figura 14), observa-se que os alunos do curso superior classificaram essa característica como excelente $(59,3 \%)$ e boa $(40,7 \%)$. Já a maioria dos professores (75\%) concordam que esse parâmetro foi de excelente qualidade. Os alunos do curso técnico, em sua maioria $(62,5 \%)$, classificaram essa característica como boa. Na média dos grupos de alunos, essa avaliação apresentou 4,3 pontos, o que significa que a sequência dos tópicos apresentou qualidade entre bom e excelente.

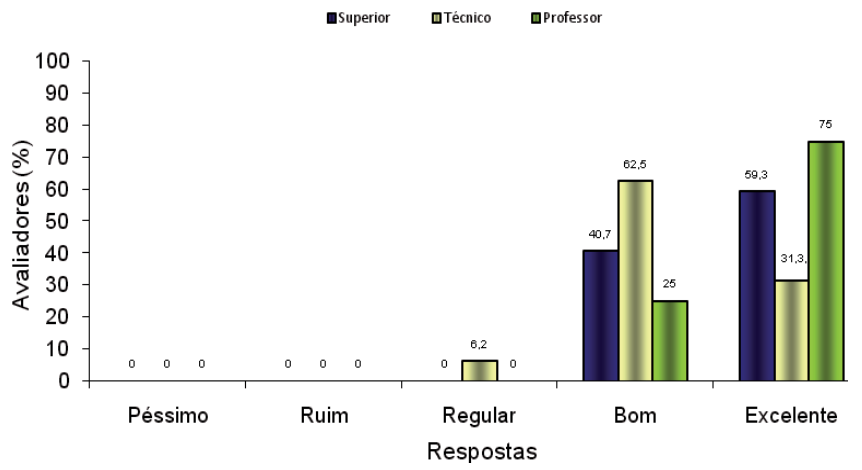

Figura 14 - Avaliação da seqüência dos tópicos do CD-ROM.

Vale salientar que a seqüência lógica de um determinado assunto, seja ela distribuída em livros, apostilas ou CD-ROM, deve ser a mais simples e eficiente o possível, pois dela depende muitas vezes o sucesso do aprendizado. Neste contexto, Dittz (2004) comenta que a carga informativa de um $C D$-ROM ou de uma página multimídia recorre a diversos sentidos ao mesmo tempo, tornando-a significativamente mais completa se comparada a um texto comum com imagens estáticas, oferecendo assim um maior poder de assimilação e retenção. 
Os recursos de multimídia também foram utilizados para o ensino de estruturas de concreto armado e protendido por Assis (2002). Esse autor verificou que $60 \%$ dos avaliadores desse tipo de recurso didático lhe atribuíram uma boa apresentação, quanto à disposição de seu conteúdo, corroborando com os resultados encontrados neste trabalho com a disciplina de topografia.

$\mathrm{Na}$ Figura 15 é destacada a avaliação da quantidade de informações contidas no CD-ROM. Nesta avaliação, tanto os alunos graduandos $(51,8 \%)$ e tecnolandos $(68,7 \%)$ quanto os professores (75\%), em sua maioria, qualificaram esta característica como de boa qualidade. Os alunos atribuíram, em média, uma nota de 4,2 pontos para a avaliação da quantidade de informações do CD-ROM.

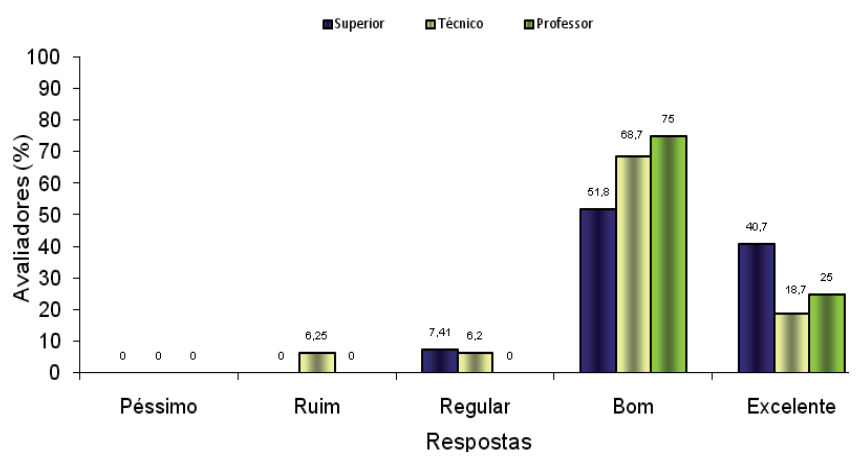

Figura 15 - Avaliação da quantidade de informações do CD-ROM.

$\mathrm{Na}$ avaliação de um sistema multimídia para ensino e aprendizado de irrigação, Oliveira et al (2002) também verificaram respostas positivas quando a quantidade de informações de seu CD-ROM foi julgado por produtores rurais e alunos de nível médio e superior, ligados às ciências agrárias. Os autores verificaram uma média de 6,8 pontos de um total de 09 pontos para essa característica avaliada. 
A qualidade das fotos digitais (Figura 16) foi excelente, segundo a avaliação da maioria dos alunos de graduação (74\%) e nível técnico $(68,7 \%)$, e por todos os professores (100\%). A média dos pontos, atribuída pelos alunos, ficou em 4,7 pontos para a qualidade das fotos utilizadas nas animações, mostrando que as mesmas atenderam ás expectativas desses avaliadores.

Resultados semelhantes também foram obtidos por ZemMascarenhas e Cassiani (2001) e por Oliveira et al (2002) quando submeteram essa característica de seus produtos multimídias ao julgamento de avaliadores externos.

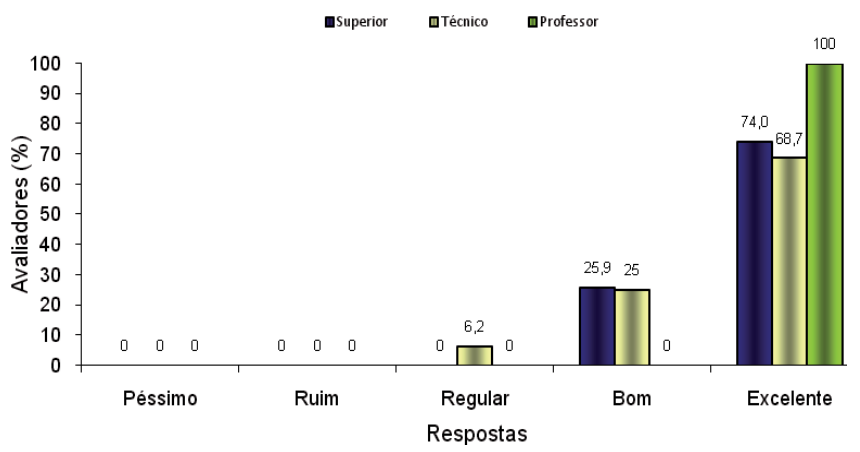

Figura 16 - Avaliação da qualidade das fotos digitais do CD-ROM.

Quanto ao tamanho e tipo das fontes utilizadas no CD-ROM, verifica-se que a maioria dos alunos (tecnolandos e graduandos) classificou esse parâmetro como bom (Figura 17). Já os professores dividiram sua opinião pela metade, indicando esse parâmetro como bom e excelente. De modo geral para os alunos, a média atribuída a essa característica foi de 4,1 pontos, segundo a escala de Likert utilizada.

O tamanho e tipo das fontes são extremamente importantes nesse tipo de instrumento, pois delas depende a facilidade ou 
dificuldade de leitura e aprendizado do aluno. Dessa forma, deve-se tornar o aplicativo o mais agradável possível para se obter um melhor aprendizado e interação homem-máquina.

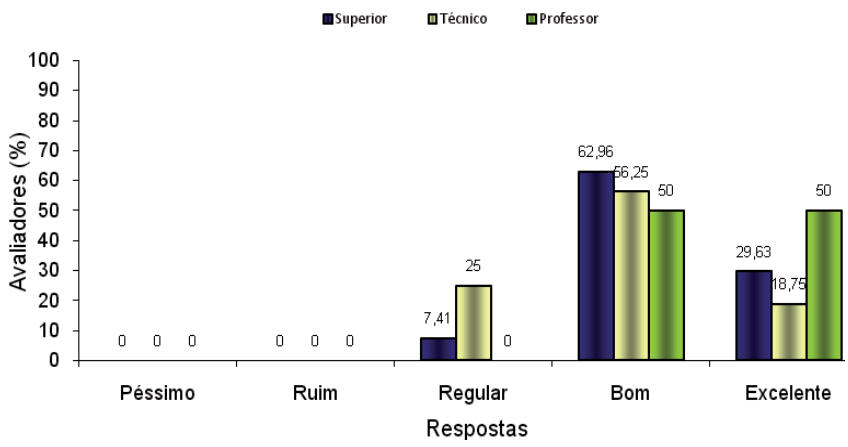

Figura 17 - Avaliação do tamanho e tipo das fontes utilizadas no CD-ROM.

O CD-ROM mostrou bom feedback para $75 \%$ dos alunos do curso técnico e, excelente para $51,85 \%$ e $75 \%$ dos graduandos e professores, respectivamente (Figura 18). Observou-se ainda que a média atribuída pelos dois grupos de alunos também foi bastante satisfatória quando os mesmos avaliaram esse feedback (4,3 pontos).

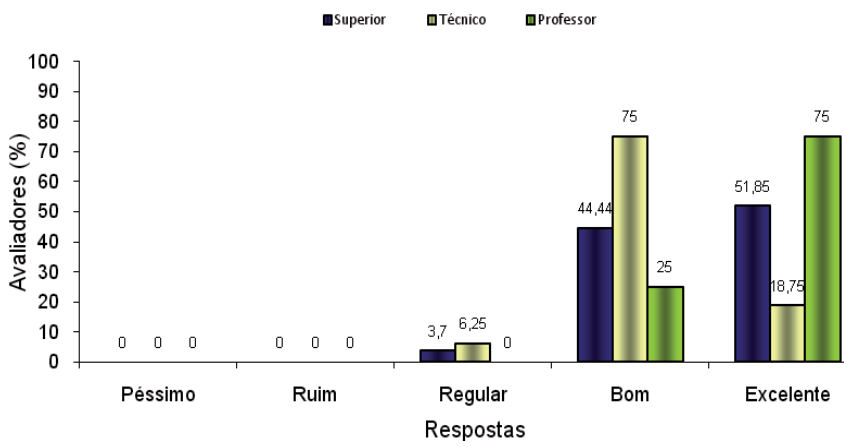

Figura 18 - Avaliação do o feed-back do CD-ROM. 
A multimídia permite que softwares sejam criados um pouco mais próximos à interface humana, possibilitando que mensagens sejam transmitidas de modo mais claro e menos cansativo que os tradicionais livros e revistas (RIBEIRO et al., 2001). Dessa forma, quanto maior a interação entre homem e máquina, no processo de ensino-aprendizagem, mais eficiente será o software utilizado pelo professor ou aluno.

A qualidade das animações gráficas foi classificada como excelente por $59,26 \%$ dos alunos de graduação e por $75 \%$ dos professores. Por outro lado, a metade dos alunos do curso técnico expressou que essa qualidade era boa, enquanto que a outra metade indicou que a mesma era excelente (Figura 19). Em média, os alunos atribuíram 4,5 pontos a qualidade das animações contidas no CD-ROM proposto.

Essa interface do produto multimídia é o conjunto dos elementos gráficos e do sistema de navegação. Muitos títulos multimídia de conteúdo vasto e aprofundado naufragam por oferecer interface de baixa qualidade, pois figuras pobres podem aborrecer o usuário pela falta de apelo visual (ASSIS, 2002).

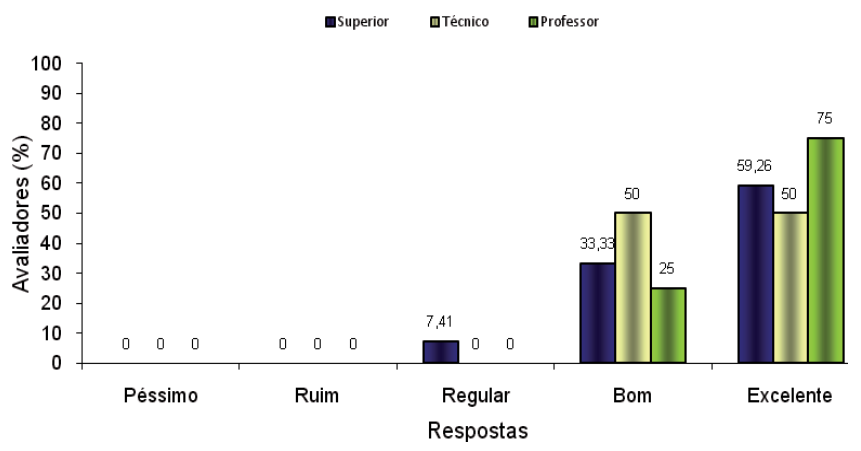

Figura 19 - Avaliação da qualidade das animações gráficas do CD-ROM. 
Para a maioria dos tecnolandos $(56,25 \%)$ e professores $(75 \%)$, foi excelente a eficiência dos textos para compreensão dos conceitos de topografia, porém a maioria dos graduandos $(66,67 \%)$ opinou que essa característica do CD-ROM era boa (Figura 20). Em termos de nota, esse atributo alcançou 4,4 pontos na escala de Likert, segundo média obtida através dos dois grupos de alunos.

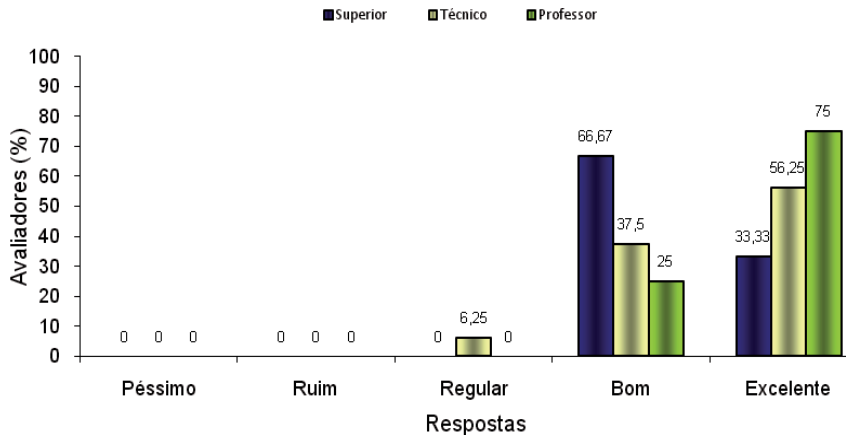

Figura 20 - Avaliação da eficiência dos textos escritos no CD-ROM para compreensão dos conceitos de topografia.

Segundo Assis (2002), a informação multimídia, mesmo sendo de natureza essencialmente eletrônica, dificilmente teria sucesso se não fosse o intenso uso do texto. Para esse autor, embora a informação sonora e videográfica façam parte do composto multimídia, o texto ainda possui uma localização fundamental neste tipo de produto. Desse modo, a multimídia pode trazer de volta a ênfase à informação escrita numa sociedade que progressivamente lê cada vez menos.

Na Figura 21, estão expressas as expectativas dos avaliadores do CD-ROM, em termos teóricos. Observa-se que os professores foram unânimes ao afirmarem uma excelente expectativa, sendo que $50 \%$ dos tecnolandos também apresentaram esta mesma opinião. Quanto aos graduandos, 66,6\% dos mesmos afirmaram uma 
boa expectativa, em termos teóricos. Em termos teóricos, foi verificada uma média de 4,3 pontos na escala utilizada.

A disciplina de topografia é, em sua maioria, lecionada de forma prática. No entanto, é preciso que o estudante tenha uma boa base teórica para aplicar seus conhecimentos quando se deparar com as aplicabilidades em campo.

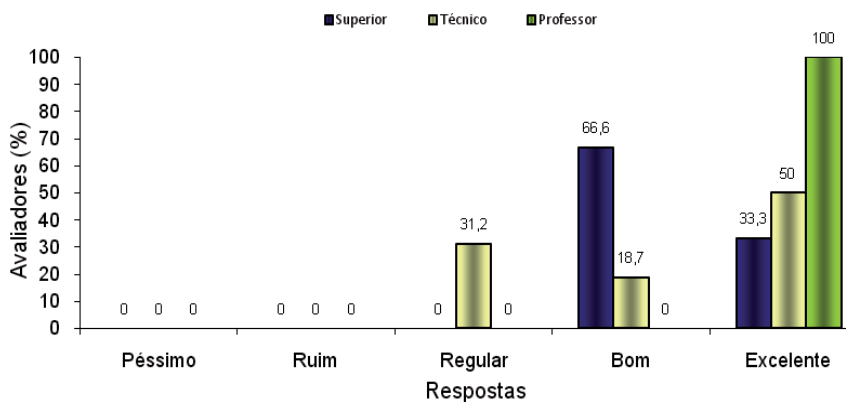

Figura 21 - Avaliação, em termos teóricos, do CD-ROM em relação às expectativas do usuário.

Em termos práticos, as expectativas do CD-ROM foram excelentes para os professores, em sua totalidade (100\%), e para tecnolandos, em sua maioria (75\%). Para os graduandos (55,5\%), essa expectativa foi considerada como boa (Figura 22). Na escala de Likert, para essa qualidade, a média dos pontos dos alunos ficou em 4,3 , o que confirma a boa aceitabilidade do produto por esses avaliadores. 


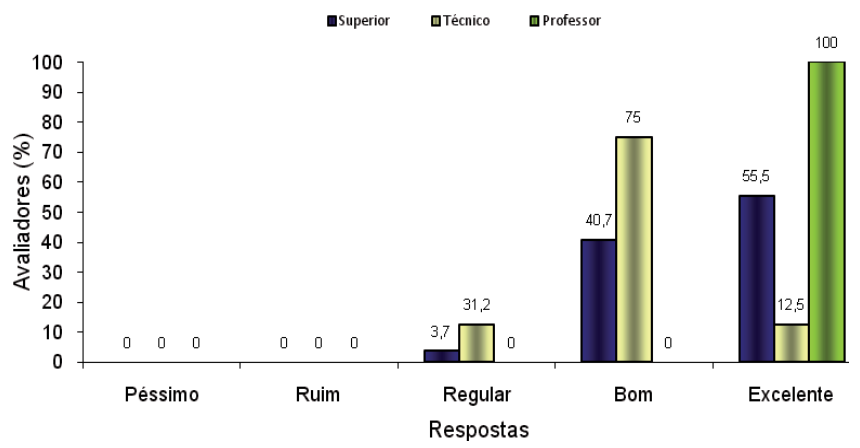

Figura 22 - Avaliação, em termos práticos, do CD-ROM em relação às expectativas do usuário.

\section{Considerações finais}

O sistema multimídia avaliado pode ser utilizado como recurso didático no ensino e aprendizado de planimetria, de maneira satisfatória, segundo avaliação de estudantes e professores da área de ciências agrárias.

O uso de material multimídia nas Ciências Agrárias tem trazido benefícios a vários alunos, ao motivá-los e ajudá-los a visualizar várias situações teóricas consideradas importantes para a formação de um bom profissional.

Os alunos demonstraram interesse neste tipo de material didático, expressando também a necessidade de ampliação de trabalhos desse tipo para os demais conceitos aplicados em topografia, assim como para as demais disciplinas do curso de licenciatura em ciências agrárias.

A utilização desse tipo de recurso computacional como ferramenta de auxílio no processo ensino-aprendizagem e a 
implementação deste instrumento no ambiente educacional vem se confirmando não somente nas universidades, mas também nos outros segmentos educacionais, como no ensino primário, secundário e até mesmo na pós-graduação. No entanto, a maioria dos docentes e alunos ainda apresenta certa resistência quanto à utilização desses recursos, uma vez que, para poder utilizá-los, são necessários alguns conhecimentos básicos sobre informática.

\section{Referências}

ASSIS, W. S. Utilização de recursos multimídia no ensino de concreto armado e protendido. 2002. 121 f. Dissertação (Mestrado em Engenharia). Escola Politécnica da Universidade de São Paulo, São Paulo, 2002.

BERENSON, M. L.; LEVINE, D. M. Basic business statistics: concepts and applitions. New Jersey: Prentice Hall, 1992.

BRANDÃO, E. J. R. Repensando modelos de avaliação do software educacional. 1998. Disponível em: <http://www.minerva.uevora.pt/ simposio/comunicacoes/artigo.html>. Acesso em: 18 de janeiro de 2008.

CARVALHO, G. M. G.; BOTELHO, F. V. U. Educação à distância: um estudo sobre expectativas dos alunos em relação ao uso do meio impresso ou eletrônico. 2000. Disponível em: <http://www.intelecto. net/ ead_textos/glaucia1.htm>. Acesso em: 10 Jan. 2008.

DITTZ, C. T. Novas tecnologias de informação e comunicação no ensino-aprendizagem de conforto luminoso em arquitetura e urbanismo. 2004. 200 f. Dissertação (Mestrado em Engenharia Civil). Universidade Estadual de Campinas, Faculdade de Engenharia Civil, Arquitetura e Urbanismo, São Paulo, 2004. 
FOCKING, G. P. Um estudo sobre técnicas de avaliação de software educacional. 2001. Disponível em: <http://www.inf.ufsc.br/ focking/ doc_finalie.html>. Acesso em: 16 Jan. 2008.

MOREIRA, M. O uso de computador na educação: pressupostos psicopedagógicos. Educação em Revista, Belo Horizonte, n.4, p. 13-17, 1986. OLIVEIRA, R. A.; MOTA, R. S.; FARIAS, C. V.; LEACIR, N. B.; RAMOS, M. M. Desenvolvimento e avaliação de sistema multimídia para ensino e aprendizado de irrigação. Revista Brasileira Engenharia Agrícola Ambiental, Campina Grande, v.6, n.3, p. 553-556, 2002.

RIBEIRO, C. A.; PINTO, C. S.; GRAZIANI, M. Y.; KATO, M. Desenvolvendo um sistema de exploração multimídia. 2001. 76 f. Monografia (Especialização em Informática Empresarial), UNESP, Guaratinguetá, 2001.

ZEM-MASCARENHAS, S. H.; CASSIANI, S. H. B. Desenvolvimento e avaliação de um software educacional para o ensino de enfermagem pediátrica. Revista Latino-americana de Enfermagem, v.9, n.6, p. 13-8, 2001. 